\title{
Responsabilidade e Imputabilidade: Diálogos entre a Psicanálise e o Direito
}

\author{
Aline Fridman \\ Natália Vidal ${ }^{1}$ \\ Universidade Federal do Rio de Janeiro
}

\begin{abstract}
RESUMO - O objetivo do artigo é tomar a atualidade dos debates sobre responsabilidade e imputabilidade para discuti-la em um diálogo entre a Psicanálise e o Direito. Revisita-se a etimologia dos vocábulos freudianos e as elucidações de Lacan, recuperando a definição de responsabilidade em Psicanálise e contrapondo-a à aplicabilidade das categorias jurídicas.Sugerese que o sujeito responsável é constituído e comandado pela adesividade (Haftbarkeit) pulsional que antecede o dever de respondere (Verantwortung).Convocado pelo trabalho da análise, pela fala, a assumir a responsabilidade por seus pensamentos imorais subjacentes aos sonhos e à vida de vigília, esse sujeito determinado pelas pulsões não é escutado pelas operações do Direito, voltadas para indicar com exatidão o imputável e o incapaz de entendimento e autodeterminação.
\end{abstract}

Palavras-chave: psicanálise, responsabilidade, direito

\section{Responsibility and Imputability: Dialogues between Psychoanalysis and Law}

\begin{abstract}
The article aims to discuss the importance of the current debates about responsibility and imputability based in a dialogue between Psychoanalysis and Law. Revisiting the etymology of freudian therms and Lacan's enlightments, authors oppose them to the applicability of those categories in the legal field. According Psychoanalysis, responsible subjects are entangled and commanded by drive's (Trieb) adhesiveness (Haftbarkeit), and this original condition precedes their duty to respondere (Verantwortung). Summoned from analytical work, subjects must take responsibility for their immoral and unconscious thoughts arising from their dreams and their awake conduct. These are the same subjects, supressed by Law's operations, which are much more interested in the subjects' capacity or incapacity of understanding, controlling their actions and taking responsibility for it.
\end{abstract}

Keywords: psychoanalysis, responsibility, law

Em Algumas notas adicionais sobre a interpretação de sonhos em seu conjunto, no item B, Freud (1925/2004) se questiona: "devemos assumir a responsabilidade pelo conteúdo dos [nossos] sonhos?” (p. 98). Essa indagação não representa o ponto de inauguração das inquietações de Freud no que diz respeito ao tema da responsabilidade (die Verantwortung/die Verantwortlichkeit) e ao que a Psicanálise poderia afirmar a partir de seu campo. Identificamos desde a Traumdeutung, ainda na revisão bibliográfica que Freud (1900/2004) fez de inúmeros autores e suas teorias, a sua preocupação com os aspectos éticos dos sonhos e com nossa responsabilidade pela inclinação moral de seu conteúdo. Esse tema perpassa de igual modo sua análise de casos clínicos, como $O$ homem dos lobos (Freud, 1918/2004) e O homem dos ratos (Freud, 1909/2004), além de outros contextos como a dinâmica da transferência, o fim da análise e o tratamento clínico e sua condução por leigos (os não-médicos, na época de Freud).

Embora tenhamos recém afirmado que $A$ responsabilidade moral pelo conteúdo dos sonhos não inaugura o trabalho de Freud (1925/2004) sobre o tema, é nele que destacamos as reflexões mais profícuas sobre o trabalho do analista e, por conseguinte do analisante, com os sonhos de figuração imoral e a responsabilidade moral (Die sittliche Verantwortung).

1 Endereço para correspondência: Rua Conde de Baependi, n. 13, Apto 701, Flamengo, Rio de Janeiro, RJ, Brasil. CEP: 22.231-140. E-mail: nvidal.ufrj@yahoo.com.br
Portanto, é partindo do ponto de vista do inconsciente e, no exemplo que isolamos, das figurações oníricas perversen, que recuperamos com Freud o que está em jogo na apropriação do assunto com os conceitos e a experiência clínica da análise. Lacan (1959-1960/1986) nos incitou a pensar que o questionamento sobre os valores morais e a relação do sujeito com a problemática da ética estão indissociados da ação terapêutica da análise (p. 106). E, no sentido dessa reflexão, o psicanalista francês recorreu aos termos originais freudianos para argumentar que a clínica psicanalítica tem uma dimensão ética que se determina pela responsabilidade do sujeito que é escutado pelo analista. Sobre os desdobramentos de tal responsabilidade trataremos melhor e oportunamente neste artigo.

Os encaminhamentos arriscados por Freud sugerem que, embora o conteúdo manifesto do sonho se apresente como imoral, os pensamentos subjacentes que lhe deram origem não seriam maus. Os sonhos com esse tipo de conteúdo manifesto seriam efeitos de superfície, que "não foram censurados porque não diziam a verdade"1 (Freud, 1925/2004, p.164), isto é, não estavam ancorados na matriz das moções pulsionais, originariamente imorais, sádicas e perversas.

Outros sonhos, de fato, têm o justo significado que expressam e não experimentam uma desfiguração, mas deles

1 "sie wurden nicht zensuriert, weil sie nicht die Wahrheit sagten" (Freud, 1925/1991, p. 566). 
o sonhador desperta angustiado, quando a censura recupera sua negligência, de forma retardatária, e a angústia substitui a desfiguração que rompeu o sono. A censura também pode se dar, com respeito a tais sonhos, de modo a produzir uma situação de expiação, de punição, apresentando-se como uma forte reação contrária à realização desses desejos imorais e perversos, sem obliterar os impulsos que lhes subjazem.

Destacamos que, nessa época, Freud (1925/2004) também relembrou um de seus primeiros corolários (Freud, 1900/2004) — o sonho como a realização de desejo (Wunschbefriedigung) — ao afirmar que certos sonhos, não interditados pela censura no aparelho anímico (Seelenapparat), viabilizam-se e efetivam a realização de desejos imorais e egoístas que se originam em um mesmo sujeito sobre o qual se poderia afirmar ter uma postura social e doméstica ilibada. O que se realiza aqui, pelo sonho, é uma dimensão desconhecida do sujeito e que o "eu metapsicológico" recusa apropriadamente.

Dessa irrupção de sentimentos e valores perversos que perturbam a consciência, nada queremos saber, pois, se não perpetramos tais desejos e cenas na vigília diurna, a eles não precisaríamos responder, isto é, responsabilizar-nos por eles. Pois "se os sonhos são o produto inexpressivo de uma atividade mental desordenada, não pode então haver fundamento para assumir responsabilidade por seu conteúdo aparente" (Freud, 1925/2004, p. 164). Os sonhos que veiculam os desejos imorais podem ser aqueles que, para driblarem a censura, atingem as figurações mais inofensivas e só revelam sua verdadeira — e má — origem quando submetidos à interpretação analítica. Sobre sonhos de tal classe, Freud comenta: "Esses delinquentes disfarçados são, como no mundo da vida de vigília, incomparavelmente mais frequentes que os declarados e confessos" (Freud, 1925/2004, p.165).

Contudo, Freud (1925/2004) abandonou esses "delinquentes disfarçados" e as figurações expressamente perversas, dedicando-se a mostrar o que deve ser o foco do analista: "as moções de desejo" (Wunsch-regungen), os "pensamentos oníricos latentes" (latenten Traumgedanken) que produzem os sonhos, sejam eles manifestamente inocentes ou imorais. Notemos aqui a importante nuance demarcada por Freud (1925/2004) entre pensamentos latentes (latenten Gedanken) e conteúdos manifestos (manifesten Inhalten) ao concluir que "o conteúdo manifesto é um engano, uma façade" (p. 164) e que o que deve ser submetido ao "exame ético" são as moções ou pensamentos oníricos latentes decantados como produto do trabalho da interpretação.

Afastando a análise das imagens oníricas e empreendendo a transição do conteúdo manifesto do sonho, inicialmente perturbador, para o desejo latente e acossador, Freud (1925/2004) deu voz à, então, incômoda temática da sexualidade humana, suas peculiaridades, sua falta de comunhão com os cânones biológicos e etológicos e os meios pelos quais ela se faz presente para o sujeito e para o analista em sua escuta. Vale mencionar que não apenas nos sonhos estavam as preocupações de Freud no destaque dado à dimensão de responsabilidade, pois ele reconheceu uma determinação inconsciente cuja estrutura também se faz ouvir em lapsos de memória, Witzen e nas paralisias corporais das histéricas, encontrando os vieses necessários e constituindo, em seu trilhamento (Bindung), o psiquismo ou, se quisermos, a subjetividade (Lacan, 1959-1960/1986).

Essa aparição da dialética entre responsabilidade moral e as figurações oníricas perversas foi essencial a um Freud arguto, ativo na espera de inserir mais uma vez, em seu debate, o campo do inconsciente. Esse movimento foi imprescindível não apenas para a construção do que é a responsabilidade em Psicanálise, isto é, para a definição do que é a categoria de responsável a partir da constituição do aparato anímico, mas também para todo o edifício da escuta de Freud e para os relatos de suas histórias clínicas (Freud, 1918/2004).

Em lugar de ceder a uma responsabilidade jurídica que visa a um indivíduo autônomo, pleno de suas faculdades de razão, consciência e memória, Freud (1925/2004) formulou uma noção de "responsabilidade que [não será mais] artificialmente limitada ao eu metapsicológico" (De Plácido e Silva, 2013, p.103), pois o sujeito, este da análise, deverá se haver com os fatos $\left(\right.$ fait $\left.^{2}\right)$, com o que faz em seus sonhos imorais, movidos por desejos inconscientes perversos, e admiti-los como concernentes ao seu eu consciente e moral, próprios a todo desejo e subjacentes a toda ação.

Freud (1925/1991) sustentou que um isolamento entre o eu e o Isso, instâncias que consistem em uma "unidade biológica isolada" ("eine biologische Einheit", p. 568), era irrealizável. Por isso, afirmou o Isso como constituinte do eu e de suas funções e atributos especiais, definindo este como uma instância fracionada em porções conscientes e inconscientes na qual localizou falhas, rupturas e intervalos, representando apenas uma parte periférica e especialmente modificada do Isso $(E S)$, submetido às suas influências e às excitações dele advindas.

Esse Ich (eu) deverá advir do lugar onde o Isso se forja, pelo Wo Es war, soll Ich werden (Lacan, 1966). O alemão de Freud nos faz sentir a literalidade, a materialidade psíquica e linguajeira dessa responsabilidade e o seu determinismo sobre o sujeito. Uma vez que é do Isso que, em um a posteriori, poder-se-á reconhecer que daí o eu terá advindo, daí terá obtido a sua causa. "Ora, essa causa é o que é abarcado pelo soll Ich, pelo devo (eu) da fórmula freudiana, que, por inverter seu sentido, faz brotar o paradoxo de um imperativo que me pressiona a assumir minha própria causalidade" (Lacan, 1966, p. 223).

Soll Ich werden, deve o eu advir do Isso, na medida em que eu me responsabilizo por esse fato psíquico originário, respondendo por minha origem, por minha natureza má, mas também moral, através da inelutabilidade que me convoca ao reconhecimento desse Isso como familiar (heimliche), como próprio (Selbst). O eu terá advindo do Isso a cada vez que eu assumir a responsabilidade pelas formações do meu inconsciente, a cada vez que eu me encarrego do trabalho (Arbeitung), no posicionamento ético de ter de responder (verantworten) pelo que em mim há de imoral (unsittliche) e de que tenho notícias pelos sonhos, atos falhos e pelo esquecimento dos nomes.

2 Que em francês se refere a fato ou feito, assim como em latim, fatio dá origem ao verbo fazer. 
Tais fatos de linguagem de nossa vida cotidiana traem, expondo o que, na incidência das pulsões, é uma dimensão ética, de responsabilidade (Haftbarkeit) que é constitutiva do sujeito, assim como concomitante à fixação (Fixierung), à adesividade (Haftbarkeit) das pulsões. Essa ideia nos permite entender o porquê de, para Freud (1925/2004), desconsiderar a existência do mal e da imoralidade dos nossos impulsos implica esquecer a própria gênese de nossa responsabilidade moral.

Com a responsabilização pela existência de desejos imorais em cada sujeito, Freud (1925/2004) construiu e ratificou mais uma vez a posição da Psicanálise frente à especificidade da noção de responsabilidade, talhada por sua investigação clínica. Contrariamente a uma moral social rígida, sedimentada em julgamentos e em padrões maniqueístas, ou a uma excessiva liberação dos costumes, a responsabilidade, em Psicanálise, assenta-se sobre a afirmação de que "obviamente, temos de nos considerar responsáveis pelos impulsos maus dos [nossos] próprios sonhos. Que mais se pode fazer com eles?" (p. 165).

Ademais se eu cedesse ao meu orgulho moral e tentasse decretar que, para fins de avaliação moral, poderia desprezar o mal no Isso sem precisar tornar meu eu responsável por ele, que utilidade isso teria para mim? A experiência me mostra que, não obstante, eu me faço responsável, que sou compelido a fazê-lo de algum modo ('dass ich gezwungen bin, es irgendwie zu tun'). (Freud, 1925/2004, p. 166, itálico nosso).

O que compele e me obriga (zwängen) a me responsabilizar, a responder com o meu dizer está relacionado ao constrangimento (Zwang) de algo (Es) que me diz, que diz de mim, à revelia do meu discurso consciente, que se pretende contínuo e coerente, mas que é rompido e desconcatenado por algo que toma a palavra exatamente no ponto em que me julgo senhor do que digo e do que penso. Consideraremos, assim, como uma injunção ${ }^{3}$ a responsabilizar-se o que Freud (1918/2004) asseverou com base em sua experiência clínica e que nos levará à segunda parte deste artigo, quando trataremos da relação entre duas intrigantes vias de debate sobre a responsabilidade e a pulsão: uma se descortina com a ideia de Haftbarkeit, da adesividade pulsional, que também carrega a conotação determinante de responsabilidade na medida em que o sujeito está colado, preso e "responsabilizado" no circuito pulsional; a outra via se refere à Verantwortung, a uma responsabilidade a ser assumida pela palavra, pela fala do eu, na análise, ao tomar como seus os pensamentos (Gedanken) imorais que se decantam do trabalho de interpretação, respondendo, por isso que " 'está' em mim (...) [ e ] 'produz efeitos' a partir de mim" (Freud, 1925/2004, p. 165). Para chegarmos a essa

3 Freud usa o particípio passado "gezwungen" para marcar a ideia do sujeito compelido, forçado por sua origem pulsional, que o obriga (zwängen), comprime-o. Ao leitor, pode parecer inevitável uma quase que imediata associação com Wiederholungszwang, compulsão à repetição, já que enfatizamos o radical Zwang que significa pressão, obrigação e tem a conotação de violência e brutalidade. Como não abordaremos diretamente a noção de Wiederholungszwang, em lugar de ceder à precisão etimológica de uma compulsão a responsabilizar-se, empregaremos a expressão injunção a responsabilizar-se, a qual também conserva a ideia de pressão e de imposição discussão, será preciso nos determos agora em considerações de natureza etimológica.

Die Verantwortungou e Die Verantwortlichkeit são os sinônimos que Freud (1925/2004) escolheu para trabalhar na seção sobre a responsabilidade moral em seu adendo com os acréscimos à teoria dos sonhos. Salientamos o radical Wort, presente e central em ambos os substantivos, e que, em alemão, quer dizer palavra, termo. Tal responsabilidade tem sublinhada (Freud, 1925/2004) a sua importância para a clínica, sobretudo, por consistir em uma responsabilidade assumida pelo dizer, pela palavra (Wort), porque o que é dito tem o valor de um ato (Lacan, 1968-1969) na medida em que o sujeito venha assumir o que dele decorre. Freud (1925/2004) nos relatou que a dimensão da responsabilidade com que trabalhou, fosse pela via-régia do sonho (Freud, 1900/2004) ou pelo estudo das perversões sexuais (Freud, 1905/1925, 1905/2004), colocara-o diante de um problema diferente daqueles apresentados por autores e escritores de outras áreas e épocas anteriores às contribuições que a Psicanálise trouxe ao conhecimento da vida psíquica.

Destacamos, assim, o trabalho onírico e as teorias sexuais para relembrar a articulação freudiana entre o sexual e os sonhos para esclarecer o que Freud pretendeu ao pontuar constantemente a necessidade de incluir uma dimensão de die Verantwortung/die Verantwortlichkeit nas construções, no contexto das análises que conduziu. Contudo, esses dois substantivos não esgotam a riqueza da inflexão que Freud deu à responsabilidade, e Lacan nos mostrou, já no contexto de Três ensaios de teoria sexual (Freud, 1905/1925, 1905/2004), o vocábulo, die Haftbarkeit, acima referido e cuja formação (Wortbildung) gramatical analisaremos a seu tempo.

Partindo de suas observações e de estudos teóricos sobre as perversões, Freud (1905/1925, 1905/2004) estabeleceu uma gênese para a sexualidade humana, localizando suas primeiras manifestações na infância e afirmando que a sexualidade do adulto é por excelência, a sexualidade infantil. Sustentando que entre o normal e o patológico há uma diferença quantitativa e não qualitativa, Freud (1905/1925, 1905/2004) se valeu de leis biológicas sobre o instinto para desenraizar a sexualidade e o desejo (referido à linguagem) de uma fixação neurofisiológica e atávica (referida à natureza).

Dessa feita, como um analista atravessado pela obra freudiana e sedimentando seu ensino como um retorno a esse legado, Lacan (1959-1960/1986) retomou essas investigações sobre a responsabilidade e a ética na experiência da análise. Sem abraçar de imediato a noção de responsabilidade em Psicanálise, partindo da expressão freudiana sittliche Verantwortung (responsabilidade moral) (Freud, 1925/2004) na referência ao conteúdo dos sonhos, Lacan (1959-60/1986) fez apelo a outros significantes, extraídos de sua leitura de Três ensaios sobre a sexualidade (Freud, 1905/1925, $1905 / 2004)^{4}$. Atendo-se à etimologia do vocabulário freudiano,Lacan (1959-60/1986) entrelaçou a fixação e a adesividade pulsional (Haftbarkeit) à responsabilidade (Verantwortung), de modo a assinalar que tal articulação extrapola a dimensão onírica.

4 Lembramos que curiosamente são do mesmo ano tanto a reformulação dos três ensaios (Freud, 1905/1925, 1905/2004) quanto o adendo à metapsicologia dos sonhos (Freud, 1925/2004). 
Na lição de 13 de janeiro de 1960, Lacan (1959-60/1986) reconheceu que, ao escrever sobre o caráter da libido, Freud $(1905 / 1925,1905 / 2004)$ fez uso de dois "termos correlativos" (Lacan, p. 106) em alemão: die Haftbarkeit e die Fixierbarkeit. Esses substantivos foram convertidos pela tradução brasileira em, respectivamente, "pertinácia" e "suscetibilidade à fixação" (Freud, 1905/1925, 1905/2004), e em "perseveração" e "fixação" pela tradução francesa (Lacan, 1959-1960/1986, p. 106). Na tradução para o castelhano de Etcheverry, temos adhesividad e fijabilidad (capacidade de fixar), também empregadas nesse último idioma como correlativas. Propomos, desse modo, uma investigação de Haftbarkeit, que nos mostrará que esta não está restrita à pertinácia ou à persévération, uma acepção predominante nas traduções brasileira (Freud, 1905/1925, 1905/1969) e francesa, que deixa de fora um aspecto fundamental que Lacan (1959-1960/1986) se dispôs a reavivar nessa época.

Se recorrermos aos dicionários em alemão (Kluge,1989), desde os mais elementares até os mais especializados, podemos enriquecer nossa leitura com informações interessantes que concernem a esse substantivo. Die Haftbarkeit pode significar responsabilidade legal ou tutela, sendo um termo bastante utilizado no Direito, em especial no sentido de que o indivíduo é responsável perante a Lei. Por ser responsável (haftbar), por ter de responder frente à Lei, ele pode ser culpabilizado (Schuld) e ser punido. Tais fontes também nos afirmam com clareza e convicção a distinção entre responsabilidade (Haftbarkeit) e culpa (die Schuld), mas não é essa a demarcação que aqui temos por objetivo.

Ainda enveredando pela etimologia, notemos que o radical haft é formador de muitos substantivos alemães. Temos, por exemplo, e não apenas a título de curiosidade, os seguintes: Die Haft: prisão, detenção; haftbar: responsável; Haftpflicht: obrigação, responsabilidade, afirmação, garantia, sinônimo de die Versicherung: contrato de seguro e do verbo versichen: segurar, garantir; Die Haftentlassung: libertação; Der Haftbefehl: mandato de prisão; Die Haftpflichtversicherung: seguro de responsabilidade civil; Der Häftling: detido, prisioneiro; Die Haftung: assunção da responsabilidade por alguém, tutela; haftend: responsável, mas também adesivo; e a construção Ich hafte dafür: eu respondo por isso, fico responsável por.

Podemos desfrutar da riqueza de haften, um verbo que significa aderir e também ficar apegado, estar agarrado, estar preso e - por quê não? - fixado. Dispõe, ainda, de uma acepção sinônima do verbo bleiben quando comporta a ação de ficar, permanecer, manter-se (anhaften), ficar entranhado, gravado. O segundo sentido para haften, e que é igualmente caro para nós, encontra relação de sinonímia com die Verantwortung (e die Verantwortlichkeit, um sinônimo de responsabilidade também presente no texto de Freud de 1925), quando é traduzido então como "resposta, réplica, reação" (Irmen \& Kollert, 2010, p. 1109) a algo ou a alguém, vindo a significar responsabilidade, no sentido de assumir uma incumbência, de estar responsável por algo, encarregarse de uma tarefa e de garantir sua realização.

A presença desses vocábulos mais ou menos aparentados pelos seus sentidos e pela ação que propalam na letra de Freud (1925/2004) nos apresenta uma dialética interessante que é a própria tessitura de seu texto, marcado por substantivos que o fixam (anhaften), que fincam caminhos bem precisos e ainda recrutam uma leitura mais atenta do idioma alemão. Notamos que, no primeiro dos três ensaios (Freud, 1905/1925, 1905/2004), abundam referências à fixação ou fixidez, ao que é fixado (die Fixierung) e não se pode revogar; no segundo, não há uma ocorrência sequer do verbo fixar (fixieren) ou do substantivo fixação; no terceiro, a fixação ainda aparece da mesma forma que na primeira seção sobre as aberrações sexuais.

Não deixa de chamar nossa atenção o fato de que, somente após ter empreendido sua construção acerca do que haveria de mais constitutivo na pulsão no resumo do texto em que recapitula suas ideias (precisamente nos dois últimos subtítulos), é que Freud (1905/1925, 1905/2004) contextualiza die Haftbarkeit ou die Fixierbarkeit, afirmando que é da adesividade/responsabilidade que decorre diretamente a "significatividade de todas as exteriorizações sexuais prematuras" (p. 221); "Die Bedeutungallerfrühzeitigen Sexualäusserungen" (Freud, 1905/1925, 1905/2004) e que ela constitui "um fator psíquico de origem desconhecida"; "einen psychischen Faktor unbekannter Herfunkt" (p. 1634).

Tal fator a que Freud (1905/1925) atribuiu, na época, um "caráter provisoriamente psicológico" (eine psychologische Vorläufigkeit; p. 1634) e cuja exaltação reconhecia nas perversões será para ele e, sobretudo, para Lacan (19591960/1986) próprio da constituição do sujeito, como uma colagem, uma adesividade pulsional: "Ich meine die erhöhte Haftbarkeit oder Fixierbarkeit dieser Eindrücke des Sexuallebens, die man bei späteren Neurotikern" (Freud, 1905[1925]/1991, p.144): "Refiro-me à elevada adesividade ou suscetibilidade à fixação que, por força, temos que supor naqueles que depois se tornam neuróticos" (Freud, 1905 [1925]/2004b, p.221).

O que há de contingente na expressão"suscetibilidade à fixação" (Fixierbarkeit), não ressalta um cunho de nãoobrigatoriedade mas destaca o movimento, a mobilidade da fixação pulsional contrariamente à fixidez instintiva. Freud $(1905 / 1925,1905 / 2004)$ assim defendeu uma desnaturalização da sexualidade, vinculando-a à mesma metáfora utilizada na descrição do aparato anímico em Além do princípio de prazer (Freud, 1920/2004), a saber, um tanque de excitações, que circulam, que formam um circuito, estabelecendo suas vias e, nessa circulação, vão fixando (fixieren) caminhos. No entanto, o caráter do investimento pulsional não representa por si só uma explicação satisfatória, já que com ele "fazemos o registro de explicação do que é em suma inexplicável" (Lacan, 1959-1960/1986, p. 106), do que, como pulsão, não é restrito ao domínio das ciências naturais. E, tampouco, pode apoiar-se no recurso à origem da história da espécie ou a uma dada configuração hereditária expressa em um segmento de genes.

Para Lacan (1959-1960/1986), a "aventura libidinal” (p. 106) em que consiste a vida do sujeito implica um trabalho que exige dele um "ter de responder por" isso que é da ordem de uma cola pulsional e de sua "elevada adesividade" (Freud, 1925/2004, p. 221). Para demonstrar o ponto preciso em que se encontrava a pungência da teoria pulsional freudiana, Lacan (1959-1960/1986) mergulhou no significante Haftbarkeit, sublinhando a conotação de responsabilidade colada ao sentido de fixação, de adesividade da pulsão, e 
afirmou que a responsabilidade está já de início colocada pela incidência da pulsão: dessa força que se encontra entre "o anímico e o somático"(Freud, 1915/2004, p. 132). Trata-se de uma responsabilidade que se aproxima de uma coação, de um constrangimento e que faz com que possamos definir o sujeito como cativo da pulsão. A responsabilidade designada por Verantwortung é diferente e posterior, atrelada ao respondere, à fala do eu, do eu que tergiversa, que denega.

Trazemos, assim, para a definição die Haftbarkeit essa designação pouco ressaltada pelos dicionários e sequer comentada pelas traduções reavivada por Lacan (19591960/1986) como dimensão de responsabilidade, sem qualquer correspondência com a busca por uma moral natural, mas que nos obriga a reconhecer que a ordem ética é edificada sobre o Stoff pulsional. Em outras palavras, a origem do sujeito é a um só tempo imoral e ética.

Por meio da etimologia alemã, é que pudemos trabalhar com a responsabilidade amarrada à incidência da pulsão. Porque a pulsão força, obriga o sujeito a se responsabilizar, ao engajamento na definição do que seria a práxis psicanalítica. Com essas considerações, antevemos não apenas a circunscrição de um domínio ético, dirigido por essa articulação força pulsional-responsabilidade, mas também podemos afirmar que a responsabilidade (die Verantwortung/ die Verantwortlichkeit) a que o sujeito se submete, ao ter de responder por algo, é causada por um constrangimento, por uma obrigação (die Haftbarkeit) originária e constitutiva, porque adere a toda matéria orgânica, a todo o vivo (Freud, 1920/2004) e falante. A dimensão de responsabilidade salientada em Haftbarkeit é muito mais uma dimensão de coerção, de constrangimento, de obrigação e em nada se aproxima de uma escolha, trata-se de algo tão originário e tão mítico quando a origem das pulsões.

A responsabilidade se impõe, nessa relação fundamental inelutável e inadiável, entre o sujeito e a pulsão. Por isso, com Lacan (1959-1960/1986), defendemos a ideia de que é porque o sujeito é engajado e compelido pela pulsão que ele deve responder, responsabilizar-se pelo mal que vem do Isso (Es). Aprisionando e detendo, a pulsão incide e constitui o sujeito como assujeitado às marcas históricas de trilhamentos (Bindungen), fixados em um processo inconsciente sobre o qual o eu consciente não arbitra (Lacan, 1959-1960/1986). Colada e indiferenciada do sujeito, a pulsão convoca à responsabilização por esse domínio inconsciente e avassalador, o mesmo das formações e do trabalho oníricos. A essa exigência de trabalho o sujeito deverá responder (verantworten) fazendo algo com as moções de seu desejo. Esse fazer é da ordem de um dizer, em análise, de uma resposta (verantworten), pela via da fala, aos imperativos dessa Haftbarkeit.

Mas a clinica que Freud inaugurou se impõe como o lugar em que essa contingência de responsabilizar-se com o dizer pode se efetivar. O sujeito, cuja "resposta a" e cuja "resposta por" é contingente, é o mesmo sobre o qual incide a força dessa cola pulsional engendrada na própria experiência da linguagem. É falando o que lhe vem à cabeça (Lacan, 1966) que o sujeito tem notícias dessa Haftbarkeit que o acossa por ser a própria matéria de que ele é feito: a linguagem, constrangendo-o no seu dizer e, na melhor das hipóteses, fazendo-o falar.
Identificamos em nosso percurso por Freud (1925/2004) vocábulos e expressões que confirmam sua erudição e o seu permanente estar à l'aise no idioma alemão. Valendo-se da riqueza etimológica de sua língua, ele nos mostrou que a fala por meio da qual respondemos e nos responsabilizamos decorre de uma condição constitutiva do sujeito que se efetiva como exigência do circuito pulsional (Lacan, 19591960/1986).

Desse modo, é forçoso reconhecer que, pelo fato de o sujeito da análise ser haftbar (responsável), nada garante que ele irá se responsabilizar pelo seu inconsciente e por seus impulsos maus. $\mathrm{O}$ trabalho da análise visa a esse sujeito contingente, que embora seja por definição haftbar, posto que Häftling (aderido) à pulsão, poderá vir a responder, sem que, contudo, haja garantias ou certezas de que o fará. A única garantia de que esse sujeito dispõe é de que ele é imprensado pela falta de garantias, pelo desamparo radical da pulsão.

\section{Os Conceitos de Responsabilidade e Indivíduo Imputável na Esfera Jurídica}

Após as apreciações acima sobre a responsabilidade e sobre o sujeito responsável na Psicanálise, passaremos agora a tratar dessas categorias e de outras a essas apensas à luz do referencial jurídico. Cabe-nos, portanto, indagar dessa área o que é a responsabilidade que ela põe em questão; quem é o sujeito responsável; para que servem tais conceitos como operadores legais e a que visam sua incidência real.

Segundo De Plácido e Silva (2013), responsabilidade é um termo tomado do latim respondere exprime a qualidade de ser responsável, tendo o sentido geral de "a obrigação de responder por alguma coisa, (...) de satisfazer a prestação (...) ou de executar o ato jurídico" (p. 713) que é imputado a um indivíduo por determinação da Justiça. Como vocábulo que tem uma acepção vasta assim como larga aplicabilidade, a responsabilidade revela o dever jurídico, no qual se coloca um indivíduo por fato ou omissão que lhe foi ou é imputado. Porém, antes de convocar à responsabilidade, é preciso inquirir sobre a definição, a identificação do indivíduo que pode ser responsabilizado, isto é, o imputável. Notamos com isso que investigar a responsabilidade e a caracterização do sujeito que pode assumi-la nos leva, no Direito, aos termos imputabilidade e capacidade.

A imputabilidade (imputabile) é definida como um conjunto de condições que são necessárias para se imputar a um indivíduo a prática de um ato punível, isto é, indicar o indivíduo que poderá ser responsabilizado por algo (De Mello, 2012; Gifis, 2013). O indivíduo imputável é aquele que poderá vir a assumir a responsabilidade por seus atos. Imputar, do latim imputare, implica atribuir, levar em conta (Luiz, 2009). Tanto no Direito Civil quanto no Penal, o termo exprime a indicação do agente, da pessoa ou da autoria a quem a responsabilidade deverá ser imposta, “assim, é condição essencial para evidência da responsabilidade, pois que não haverá esta quando não se possa imputar à pessoa o fato de que resultou a obrigação de ressarcir o dano ou responder pela sanção legal" (De Plácido e Silva, 2013, p. 418). Evitemos, assim, uma pronta assimilação ou superposição entre imputabilidade e responsabilidade. 
Voltemos à expressão latina respondere, que costumava ser uma das atribuições dos juristas romanos, que davam consultas e respondiam aos casos que lhes eram apresentados (Luiz, 2009). A mesma origina o substantivo responsabilidade, empregado juridicamente e que abrange as funções de "dar a resposta ou depor, afirmando ou negando as perguntas que são feitas. (...); replicar ou refutar, quando se refere às objeções ou aos argumentos contrários de outrem; representar quando a pessoa é colocada na posição de outra"; e, por fim, assumir a responsabilidade: "pagar pelo que fez" (De Plácido e Silva, 2013, p. 713) ou deixou de fazer.

A capacidade, por sua vez, é a qualidade do indivíduo juridicamente capaz, isto é, aquele que está apto a "reger seus próprios negócios e interesses" (De Mello, 2012, p. 41) e responder pelo que a eles concerne. A capacidade penal, por exemplo, distingue-se da imputabilidade, pois a primeira se refere a um momento anterior ao ato delinquente, enquanto que a segunda diz respeito ao intervalo de tempo em que dura o delito. Assim, aquele a quem não se pode cobrar a responsabilidade, o sujeito incapaz de responder, é o indivíduo inimputável, que se opõe ao agente responsável.

A isenção ou redução da pena se aplica aos casos em que o agente se achava "inteiramente incapaz" ou "não era inteiramente capaz de entender [momento intelectual] o caráter ilícito do fato ou de determinar-se [momento volitivo] de acordo com esse entendimento" (Parágrafo 26 do Código Penal, citado por Chalub, 2004, p. 130). Isso implicaria, para a Psiquiatria Legal, que a capacidade ou a imputabilidade é conferida, refutada ou negada, por critério biopsicológico após a conclusão pericial laudada por um especialista, que atribui essa qualidade a outrem, ao indivíduo, de modo que se possa asseverar que ele possa responder diante da Lei.

Frente ao acima exposto, para ser considerado responsável na maioria dos dispositivos jurídicos ocidentais contemporâneos, temos que o indivíduo deve ter sido qualificado como "capaz de entender o caráter ilícito do fato ou de determinar-se de acordo com esse entendimento" (artigo 26 do Código Penal). A partir da Modernidade, temos uma articulação entre pensamento, sujeito e responsabilidade no campo da razão e sua exclusão do domínio de qualquer outra forma de relação com o saber em que uma racionalidade consciente não se faça presente, como, por exemplo, na experiência da loucura, mas não somente nesta, tal como pudemos evidenciar em nosso recurso à Freud (1925/2004) e ao que ele nos traz sobre a responsabilidade do sujeito diante dos sonhos, do sintoma, dos chistes e atos falhos (Birman, 2005).

Do racionalismo moderno que anima o Direito contemporâneo, origina-se o fundamento teórico do dispositivo da Medida de Segurança existente no Código Penal Brasileiro (Vidal, 2012). Segundo esse dispositivo, um sujeito é passível de ser desresponsabilizado por seu delito perante a Justiça na medida em que não possuía, à época dos fatos, as supracitadas capacidades de entendimento e autodeterminação.

O percurso que empreendemos acerca da adesividade do sujeito ao circuito pulsional é particularmente interessante para problematizarmos não exclusivamente a responsabilidade, mas a imputabilidade na esfera legal tal qual ela se delineia ainda na atualidade. Nosso trabalho propõe com isso um redimensionamento da questão, já que procuramos mostrar que o sujeito da análise não é exatamente o sujeito considerado imputável ou inimputável. Ao mesmo tempo em que o laudo atesta a capacidade ou a incapacidade do indivíduo no momento simultâneo ao delito, ele perde o que para a Psicanálise é um sujeito que emerge como efeito do próprio ato. A perícia tem o objetivo de reconhecer a imputabilidade ou recusá-la, e, dessa forma, instar o indivíduo a responder por seus atos. Porém, ainda que esse indivíduo seja encaminhado a tratamento e acompanhamento psiquiátrico e/ou psicológico, esse sujeito da transgressão está perdido para o Direito. Isso porque seus operadores se dirigem ao indivíduo lúcido ou mentalmente transtornado e não ao sujeito do inconsciente a que a análise empresta sua escuta. $\mathrm{O}$ que a Psicanálise revela, no entanto, é que não há como dissociar o sujeito do ato e sua responsabilidade, mesmo que ele seja tomado como inimputável ou parcialmente imputável, porque aqui se trata de uma responsabilidade de outra ordem, a ordem inscrita pela sua constituição como sujeito da Linguagem, dimensão que a pulsão presentifica.

\section{Para Encaminhar o Debate}

Não ignoramos o destaque do campo da Psiquiatria Legal ou Forense, área de interface entre o Direito e a Psiquiatria. É pregnante a relevância de suas definições e a dinâmica de que gozam, nessa disciplina, a responsabilidade, a imputabilidade e a capacidade, como resultantes de um processo legal e médico de avaliação, envolvendo diversos “aspectos contextuais e psicopatológicos e a verdadeira responsabilidade de cada um pela conduta delituosa tomada" (Moraes \& Fridman, 2004, p. 22). Todavia, adentrar por esse domínio ultrapassaria o objetivo deste artigo de reunir algumas concepções mais ligadas aos fundamentos filosóficos do Direito para contrapô-los aos fundamentos clínicos da Psicanálise.

A responsabilidade pelo conteúdo dos sonhos e a constituição do sujeito no circuito pulsional, decerto, não são alvo do Código Penal ou do Código Internacional de Doenças (CID-10), que se restringem às condutas de vigília contraventoras, ilícitas e criminais (citado por Chalub, 2004). A Psicanálise, ao contrário, nelas muitas vezes identifica determinantes inconscientes, tal como podemos identificar na referência de Freud (1900/2004) aos sonhos de criminosos em decorrência do sentimento de culpa, nos quais esse último fator se apresenta não como resultante da conduta delituosa, mas, antes, como seu motor. Contudo, podemos esboçar um conceito de indivíduo imputável e, por conseguinte, responsável, pautado pelos parâmetros legais e critérios contemplados nos laudos periciais.

Assim, do breve panorama que trouxemos, destacamos que os termos pessoa e indivíduo são bastante empregados para referir-se ao autor do ato, ao indivíduo unificado, célula biopsicossocial que é o sujeito do Direito desde o advento do racionalismo moderno (Vidal, 2012).Cumprindo as condições que o tornam capaz de ser responsável, ele se diferencia radicalmente do sujeito da análise, que, por sua própria posição, é sempre responsável (Lacan, 1966), na medida 
em que tem seu discurso engendrado e entrecortado por um discurso Outro, do inconsciente, nos sonhos e na vigília, pois constitutivo do funcionamento psíquico (Freud, 1915/2004).

Desse modo, a proposta do artigo, e também sua novidade, consistiu em problematizar a noção de Haftbarkeit, uma responsabilidade mais originária, anterior à Verantwortung, indissociada da força pulsional que opera como pressão, injunção e violência. O sujeito comandado e compelido pela pulsão é sempre responsável, porque nele a pulsão persevera como uma coação, exigindo uma resposta ética. Podemos, assim, afirmar que o percurso de Freud, ao fundar a Psicanálise, surpreendeu e continua a surpreender por ter instaurado com sua clínica uma ética que inclui, que repatria o mal e a dimensão tempestuosa e em nada apaziguadora do desejo. Debruçando-se sobre os sonhos, os sintomas e os atos falhos, Freud (1900/2004) pôde nos dar notícias dessa razão inconsciente, cujas formações são regidas por leis que não seguem um curso aleatório e que determinam o sujeito sem isentá-lo da responsabilidade pelo que vem do inconsciente.

Enquanto a produção do sujeito do Direito visa aos ditames da Lei e à boa regência do contrato social, a operação da análise visa à produção de um sujeito sem pragmatismo legal, que encontra sua importância na medida em que a escuta do analista e o trabalho da análise, o trabalho que consiste em um dizer, visam a uma realização subjetiva (Lacan, 1966). Tal operação analítica, além de fornecer critérios e caminhos investigativos, particulares a cada análise, dá lugar ao inconsciente sem elidir a responsabilidade do sujeito. A elisão temporária da consciência durante uma transgressão ou um sonho imoral não libera o sujeito de sua responsabilidade, porque o imperativo da análise, sua regra de associar livremente não exime o sujeito de ter de responder a seus impulsos sejam eles ordinários ou criminalizáveis.

Notamos assim que o sujeito do Direito, capaz, imputável ou responsável é uma produção da técnica, dos instrumentos de que dispõe a esfera jurídica para fazer pagar aquele que se revela imputável, isto é, aquele que vai sofrer a imputação da responsabilidade por suas ações ou omissões. Esse sujeito obtido por avaliações legais não é o mesmo sujeito que a Psicanálise tomará então como responsável e cuja condição de sujeito é determinada e confundida com a definição de responsabilidade (die Haftbarkeit). A resposta do sujeito que se responsabiliza pelo "mal" que há nele como o que lhe é mais próprio, não lhe assegura uma cura no sentido de erradicação dos sintomas ou das queixas que o levaram a procurar um analista. Essa resposta é sempre pontual, está sempre a se recolocar e não se restringe a uma resposta à Lei, à Justiça, mas se reporta a uma fala construída como resposta em um endereçamento ao analista, implicando, na melhor das hipóteses, um questionamento e uma retificação das posições assumidas ou recusadas pelo sujeito. Isentado do dever de responder ou parcialmente responsável, considerado incapaz por doença ou retardo mental, o sujeito que é excluído ou inserido no regime correcional pela Lei, é o sujeito em que se engancha a tirania das pulsões, das moções pulsionais inconscientes. $\mathrm{O}$ dispositivo analítico, ao dar lugar à fala, a esses impulsos, não pretende reabilitá-lo, mas escutá-lo falar qualquer coisa, visto que a materialidade da linguagem, da fala, institui-se como princípio regente do aparelho psíquico.
Para a Psicanálise, o sujeito haftbar, que hafte dafür (responde por isso), é o sujeito da análise, ao qual a escuta analítica deverá visar. Esse sujeito é compelido a responder (verantworten), mesmo sem deliberadamente o querer, pois tal responsabilidade/adesividade (dieHaftbarkeit) se apresenta e persevera no ato falho, na troca de nomes, no sentido e no humor, depreendidos das piadas e dos trocadilhos, nos sonhos. Nessas formações do inconsciente, o sujeito aparece preso, aderido (Häftling), determinado pelas pulsões que o constituem e o causam como sujeito que, mais do que responsável (haftbar), deverá se responsabilizar.

Se nos mantivermos nas linhas de Freud (1925/2004), em uma aproximação com o sentido de die Verantwortung, podemos reafirmar que a garantia legal é bastante distinta da responsabilidade em causa na Psicanálise. Pois ao contrário de Haftpflichtkeit (segurança) ou Versicherung (garantia) longe de assegurar ou prometer algo ao analisante, a análise põe em risco, põe a perder as construções imaginárias, os mitos individuais que um sujeito leva para a clínica (Fridman, 2013).

\section{Referências}

Birman, J. (2005). O mal-estar na modernidade e a psicanálise: A psicanálise à prova do social. Physis: Revista de Saúde Coletiva, 15, 203-224.

Chalub, M. (2004). Perícias de responsabilidade penal e de dependência química. In J.C.V. Taborda, M. Chalub, \& Abdalla-Filho, E. (Orgs.), Psiquiatria Forense. Porto Alegre: Artmed.

De Mello, M. C. (2012). Dicionário Jurídico (10ª Ed.). Vila Mariana: Editora Método (Grupo Gen).

De Plácido e Silva, O. J. (2013). Vocabulário Jurídico. (30ª Ed.). Rio de Janeiro: Editora Forense.

Freud, S. (1925). Drei Abhandlungen zur Sexualtheorie. Sigmund Freud GesammelteWerke (1890-1939). Retirado de de: http:// www.staferla.free.fr. (Original publicado em 1905)

Freud, S. (2004). Três ensaios sobre a teoria da sexualidade, In J. Strachey (Ed.)., Edição Standard Brasileira das obras psicológicas completas de Sigmund Freud. (vol. 7, pp. 123-250, J.Salomão, Trad.). Rio de Janeiro: Imago. (Original publicado em 1905).

Freud, S. (2004). La interpretación de los sueños. Sigmund Freud Obras Completas (vol. 4, pp. 1-343, J. Etcheverry, Trad.). Buenos Aires: Amorrortu. (Original publicado em 1900)

Freud, S. (2004). Tres ensayos de teoria sexual. Sigmund Freud Obras Completas (vol. 7, pp. 111-222, J. Etcheverry, Trad). Buenos Aires: Amorrortu. (Original publicado em 1905)

Freud, S. (2004). A propósito de un caso de neurosis obsesiva (el Hombre de las Ratas). Sigmund Freud Obras Completas (vol. 10, pp. 123-196, J. Etcheverry, Trad.). Buenos Aires: Amorrortu. (Original publicado em 1909)

Freud, S. (2004). Pulsiones y destinos de pulsión. Sigmund Freud Obras Completas, (vol. 14, pp. 123-137, J. Etcheverry, Trad.). Buenos Aires: Amorrortu. (Original publicado em 1915)

Freud, S. (2004). Lo inconciente. Sigmund Freud Obras Completas (vol. 14, pp.161-213, J. Etcheverry, Trad.). Buenos Aires: Amorrortu Editores. (Original publicado em 1915) 
Freud, S. (2004). De la historia de una neurosis infantil (caso del 'Hombre de los Lobos'). Sigmund Freud Obras Completas, (vol. 17, pp. 1-111, J. Etcheverry, Trad.). Buenos Aires: Amorrortu. (Original publicado em 1918)

Freud, S. (2004). Más allá del principio de placer. Sigmund Freud Obras Completas, (vol. 18, pp. 1-62, J. Etcheverry, Trad.). Buenos Aires: Amorrortu. (Original publicado em 1920)

Freud, S. (2004). Algunas notas adicionales a la interpretación de los sueños en su conjunto. Sigmund Freud Obras Completas, (vol.19, pp. 61-69, J. Etcheverry, Trad.). Buenos Aires: Amorrortu. (Original publicado em 1925)

Freud, S. (1991). Einige Nachträge zum ganzen der Traumdeutung. Sigmund Freud Studien ausgabe Werke aus den Jahren 1925-1931 (Vol. 10, pp. 561-573). Frankfurt: Fischer Verlag. (Original publicado em 1925)

Fridman, A. (2013). O caráter perturbador da verdade em Psicanálise (Tese de Doutorado). Programa de Pós-graduação em Teoria Psicanalítica, Instituto de Psicologia da Universidade Federal do Rio de Janeiro, Rio de Janeiro.

Gifis, S. (2013). Barron's law dictionary (6th Ed.). New York: Barron's Educational Series, Inc.

Irmen, F. \& Kollert, A. (2010). Langenscheidt Taschen -wörterbuch Portugiesisch-Deutsch, Dicionário de Bolso Português. ( $9^{\mathrm{a}} \mathrm{Ed}$.) Berlin: Langenscheidt.
Kluge, F. (1989). Etymologisches Wörterbuch der deutschen Sprache. Berlin: Walter Gruyter.

Lacan, J. (1986). La Pulsion et les leurres. In Le séminaire, livre VII:L'éthique de la Psychanalyse (pp. 105-119). Paris: Éditions du Seuil. (Original publicado em 1959-1960)

Lacan, J. (1966). La Science et la vérité. In Écrits II ( pp. 219-244). Paris : Éditions du Seuil.

Lacan, J. (1968-1969). D'un Autre à l'autre. Recuperado de http:// www.staferla.free.fr.

Luiz, A. F. (2009). Dicionário de expressões latinas.(2 $\left.{ }^{\mathrm{a}} \mathrm{Ed}\right)$.São Paulo: Editora Atlas.

Magalhães, E. C. P., \& Magalhães, M. C. P. (2011). Dicionário jurídico Piragibe (2 $2^{\text {a }}$ Ed.). Rio de Janeiro: Editora Lumen Juris.

Moraes, T., \& Fridman, S. (2004). Medicina forense, Psiquiatria forense e Lei. In J. C. V. Taborda, M. Chalub, \& E. AbdallaFilho (Org.), Psiquiatria Forense. Porto Alegre: Editora Artmed.

Vidal, N. (2012). O real na letra da Lei: De uma escrita que dê lugar ao sujeito (Dissertação de Mestrado). Programa de Pósgraduação em Teoria Psicanalítica, Instituto de Psicologia da Universidade Federal do Rio de Janeiro, Rio de Janeiro.

Recebido em 21.02.2014

Primeira decisão editorial em 26.06.2015

Versão final em 06.07.2015

Aceito em 04.05.2016 